\title{
Community Attitudes Toward People Receiving Unemployment Benefits: Does Volunteering Change Perceptions?
}

\section{Timothy P. Schofield \& Peter Butterworth}

To cite this article: Timothy P. Schofield \& Peter Butterworth (2018) Community Attitudes Toward People Receiving Unemployment Benefits: Does Volunteering Change Perceptions?, Basic and Applied Social Psychology, 40:5, 279-292, DOI: 10.1080/01973533.2018.1496335

To link to this article: https://doi.org/10.1080/01973533.2018.1496335

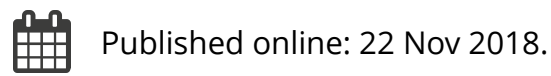

Submit your article to this journal 준

Џll Article views: 272

Q View related articles ¿

View Crossmark data ¿

Citing articles: 1 View citing articles $\sqsubset$ 


\title{
Community Attitudes Toward People Receiving Unemployment Benefits: Does Volunteering Change Perceptions?
}

\author{
Timothy P. Schofield ${ }^{\mathrm{a}}$ (D) and Peter Butterworth ${ }^{\mathrm{a}, \mathrm{b}}$ \\ ${ }^{a}$ Centre for Mental Health, Melbourne School of Population and Global Health, The University of Melbourne; ${ }^{b}$ Melbourne Institute of \\ Applied Economic and Social Research, The University of Melbourne
}

\begin{abstract}
People receiving government income support due to unemployment are sometimes required to participate in activities such as volunteering. These "mutual obligation" requirements have community support, but the effect of volunteering on benefit recipients is unclear. In three person-perception experiments $(N=222,533,934)$, we considered whether volunteering overcomes negative evaluations of unemployed benefit recipients. Volunteering increased the extent to which benefit recipients were considered suitable workers and likeable, but these effects also generalized to non-recipients. Results suggest that volunteering may compensate for attitudinal barriers arising from welfare stigma that represents a barrier for employment.
\end{abstract}

Paid employment and (unpaid) volunteering are both socially valued and productive activities, and both can be considered forms of work (Metzer, 2006). Although volunteering does not provide the individual with remuneration, it does bring that person a range of other benefits (UN Volunteers, 1999) and makes a valuable contribution to society (Independent Sector, 2001; Ironmonger, 1998). Volunteering and employment are also both a focus of current employment programs and policy. A number of countries mandate participation in activities such as volunteering and community work for those in receipt of government payments, such as unemployment benefits (e.g., Germany and the Netherlands: Bruttel \& Sol, 2006; Australia: Cordingley, 1997; United States and Canada: Crisp \& Fletcher, 2008; United Kingdom: Kamerāde \& Paine, 2014). The goals of such "mutual obligation" or workfare policies are broadly to provide an opportunity for those who receive benefits to build skills and increase their employment prospects, improve their health and psychological well-being, and contribute back to society and demonstrate reciprocity (Abetz, 2014; McClure, Sinclair, \& Aird, 2015). Research shows that the general public is broadly supportive of mutual obligation requirements (Humpage, 2011; Saunders, 2002; Schofield \& Butterworth, 2015; Shapiro, Patterson, Russell, \& Young, 1987; Van Oorschot, 1998). The present project extends this prior research beyond assessment of public opinion by examining how perceptions of unemployed welfare recipients are influenced by their volunteering behavior.

The reasons why people volunteer (Clary \& Snyder, 1999; Houle, Sagarin, \& Kaplan, 2005) and the benefits that individuals may derive from volunteering (Kamerāde \& Paine, 2014; UN Volunteers, 1999) align with the stated goals of mutual obligation policies (e.g., McClure et al., 2015). People often report volunteering to acquire skills and knowledge and enhance their career development prospects (Clary \& Snyder, 1999; Houle et al., 2005). Consistent with this, mutual obligation activities are argued to provide unemployed welfare recipients an opportunity to "improve their skills and increase their employment prospects" (Department of Social Services, 2016). This may be through developing "soft" skills such as adherence to routine and understanding of workplace norms (Laker \& Powell, 2011; Newton, Oakley, \& Pollard, 2011; Robles, 2012) or "hard" skills directly tied to industry and occupational requirements (Cook \& Jackson, 2006; Laker \& Powell, 2011). People also report volunteering to enhance their self-esteem (Clary \& Snyder, 1999; Houle et al., 2005). Again, beliefs that these are the pathways to improvement are reflected in the media statements of politicians (e.g., Abetz, 2014) and in policy documents about how mutual obligation

CONTACT Timothy P. Schofield timothy.schofield@unimelb.edu.au C Centre for Mental Health, Melbourne School of Population and Global Health, The University of Melbourne, Level 4, 207 Bouverie Street, Melbourne, Victoria 3010, +61 38344 7838, Australia.

(c) 2018 Taylor \& Francis Group, LLC 
requirements improve the self-esteem and psychological wellbeing of unemployed welfare recipients (e.g., McClure et al., 2015). Finally, people say they volunteer for altruistic reasons and to benefit their communities (Clary \& Snyder, 1999; Houle et al., 2005). A key objective of mutual obligation requirements is to ensure welfare recipients "contribute something to their community" (Department of Social Services, 2016) such that the provision of government support is in line with community expectations of individual responsibility and reciprocity (McClure et al., 2015).

Although there is broad community support for mutual obligation requirements (Humpage, 2011; Saunders, 2002; Schofield \& Butterworth, 2015; Shapiro et al., 1987; Van Oorschot, 1998), the degree of support varies with the demographic characteristics of recipients. Saunders (2002), for instance, asked a representative Australian sample about their support for mutual obligation activities (e.g., participation in training, unpaid community work) for different groups of unemployed individuals. Support for the application of mutual obligations to the young and long-term unemployed were greatest. These findings replicated earlier Dutch findings of Van Oorschot (1998).

Despite community support for such requirements, evidence that they help people return to work is mixed. Two recent epidemiological cohort studies have suggested that volunteering is also associated with an increased likelihood of future employment among those who are unemployed (Konstam, Tomek, Celen-Demirtas, \& Sweeney, 2015; Spera, Ghertner, Nerino, \& DiTommaso, 2015; but see Kamerāde \& Paine, 2014). Other studies have sometimes found small or negligible improvements in employability relevant dimensions, like self-efficacy (Gay, 1998; Kellard, Honey, McNamara, Biddle, \& Gray, 2015; vinspired, 2008; but see Warburton \& Smith, 2003). The evaluation of some mutual obligation programs has, however, shown lower rates of employment and transitions off of welfare (Borland \& Tseng, 2011). Investing time in meeting the requirements of a mutual obligations program may help to develop a person's work skills but reduces the hours in which participants can engage in job search activities (see Borland \& Tseng, 2011).

Another way that mutual obligation activities, such as volunteering, may have a positive effect is by challenging the negative stereotypes of welfare recipients. The typical welfare recipient is seen as low in warmth, competence, and Conscientiousness, as a poorer worker, and as less human than other people (Bye, Herrebr $\oslash$ den, Hjetland, R $\oslash$ yset, \& Westby, 2014;
Fiske, Cuddy, Glick, \& Xu, 2002; Schofield, Haslam, \& Butterworth, unpublished manuscript submitted for publication). This perceived personality is likely to reduce rates of job offers. However, it is unknown whether involvement in activities such as volunteering directly challenges these perceptions or can be used to compensate for the influence of welfare receipt. Volunteering might challenge perceptions of welfare recipients if it demonstrates their engagement in worklike behavior, or it may compensate for them if volunteering is seen as demonstrating reciprocity. We suspect that volunteering will either challenge or compensate for the negative evaluations of welfare recipients because employers claim to view job seekers with a history of volunteering more positively (vinspired, 2008). As far as we are aware, this has not been tested experimentally. Shore and Tashchian (2013) examined how volunteering affected human resources students' perceptions of unemployed job candidates by having them read résumés submitted in application for an accounting role. Some of these résumés detailed volunteering, whereas others did not. Participants indicated whether they considered the candidates highly qualified, would grant the candidate an interview, and award them the position. Across the three employability outcomes, the students rated the résumés of those with volunteering experience more highly, even when the volunteering was career irrelevant. However, this study examined unemployment and not receipt of government benefits, and relied on a student sample.

In the present project we use three personperception experiments to examine the effect of volunteering on the stereotyping of recipients of unemployment benefits. We focus on three outcomes: rated work suitability, Conscientiousness, and humanness. Conscientiousness is a personality trait associated with positive employment outcomes (Barrick, Mount, \& Judge, 2001) and employment (Boyce, Wood, Daly, \& Sedikides, 2015). It is highly correlated with ratings of worker suitability and perceived as low among current recipients of unemployment benefits (Schofield et al., unpublished manuscript submitted for publication). Groups stereotyped as low in warmth and competence, including recipients of unemployment benefits, are also seen as less human than other groups (Harris \& Fiske, 2011; Schofield et al., unpublished manuscript submitted for publication; Waytz \& Epley, 2012). Volunteering may change both of these ratings, via demonstrations of reciprocity, a positive attitude, and demonstrating close proximity to the in-group (Van Oorschot, 2000). Experiments 1 and 2 were approved by the Australian National University 
Delegated Human Research Ethics Committee (protocol \#2015/594) and Experiment 3 by the University of Melbourne's Human Research Ethics Committee (protocol \#1750220.2). All were conducted within American Psychological Association guidelines; we report all measures, manipulations and exclusions, and deviations from preregistered proposals. ${ }^{1}$

\section{Experiment 1}

\section{Method}

\section{Sampling}

We sought to recruit a sample of 240 individuals from within the United States via Human Intelligence Tasks (HITs) on Amazon's Mechanical Turk (MTurk) service. Data from 261 respondents were received; five people did not give permission for their data to be analyzed or retained, and their data were destroyed. Of the remaining cases, 229 had IP addresses confirming a U.S. location. Based on respondent IP addresses, seven of these respondents appeared to be duplicates, and only the first response was retained.

\section{Participants}

The analyzed sample comprised 222 participants recruited from the United States via MTurk (119 female, 102 male, 1 other). These participants had a mean age of $32.86(S D=11.73$, range $=18-71)$.

\section{Materials}

Participants were first presented with a vignette describing the weekend of a young man with no tertiary qualifications and in receipt of unemployment benefits to read at their own pace. This profile reflected the fact that young men without tertiary education, the most common education level among those older than 25, have the highest risk of unemployment in the post-college years (Australian Bureau of Statistics, 2016; Bureau of Labor Statistics, 2017; U.S. Census Bureau, 2017). Our prior research suggests that varying the age, gender, relationship status, and weekend activities has main effects on ratings of the character's personality but does not modify the effect of benefits received during unemployment (Schofield et al., unpublished manuscript submitted for publication). Here, however, we embedded the experimental manipulation within only this single vignette. This specific vignette is well placed for testing our hypotheses because data from two pilot studies $(N=109$; $N=39$, respectively) indicated that participants endorsed community work requirements for this specific vignette character $\left(d_{\text {Pilot1 }}=0.29\right)$ and believed that volunteering would increase their employability $\left(d_{\text {Pilot1 }}=0.95, d_{\text {Pilot2 }}=1.27\right)$ and likability $\left(d_{\text {Pilot1 }}=\right.$ $\left.1.06, d_{\text {Pilot2 }}=1.78\right)^{2}$

A single two-level, between-person experimental manipulation randomly varied whether the character was described as on unemployed and receiving benefits ( $\mathrm{n}=110)$, that is, "He is currently unemployed, and has been receiving government benefits for the last 6 months due to his unemployment," or as volunteering while on unemployment benefits $(n=109)$, that is, "He is currently unemployed but volunteers with a charity a few days every week, and has been receiving government benefits for the last 6 months due to his unemployment." The vignette this manipulation was embedded within is presented next:

John is a 29 year old man who finished high school but didn't go to college. [randomly varied condition text]. John is single and plays soccer with his local club on Saturday afternoons. This weekend his team won an important game. After their game each week the team normally goes to the local sports bar for a couple of beers, but John doesn't normally join them. This week he decided to join them to celebrate the victory and had a really good time. On Sunday he enjoyed a sleep-in and went for a walk at the park, before coming home and catching up on house chores. He spent the evening watching a superhero movie on TV and got an early night.

After self-paced reading of the vignette, and as outlined in the preregistration, participants were presented with three vignette comprehension questions. These questions were "How old was the person in the story?" "What sport did the person in the story play?" and "What genre/type of movie did the person in the story watch?" Those who incorrectly answered all three vignette comprehension questions were excluded from analysis $(n=2)$. It was decided that there was no notable difference between the experimental conditions in the number of comprehension questions answered correctly $(d=0.11){ }^{3}$

Participants then responded to 20 items, presented in a random order, on a 5-point scale labeled from 1 'strongly disagree to 5 'strongly agree. Ten items were an adaptation of the Ten-Item-Personality-Inventory (Gosling, Rentfrow, \& Swann, 2003), a self-oriented personality scale, to other-oriented wording (i.e., "I felt like the person in the story was ..."). Two items were presented for each trait in the Big Five, with their mean score (after appropriate reverse scoring) indicating greater levels of the trait. The two items assessing each trait were appropriately correlated with associations of a reasonable size: Openness to Experience $(r=.35)$, Conscientiousness $(r=.69)$, 
Table 1. By condition descriptive breakdown and analysis of differences on rated characteristics in Experiment 1.

\begin{tabular}{lccc}
\hline & Unemployed $M(S D)$ & Volunteer $M(S D)$ & $d$ \\
\hline Personality outcomes & & & \\
$\quad$ Openness to Experience & $3.11(0.79)$ & $3.11(0.72)$ & 0.00 \\
$\quad$ Conscientiousness & $3.37(0.82)$ & $3.50(0.98)$ & 0.14 \\
$\quad$ Extraversion & $2.78(0.88)$ & $2.83(0.83)$ & 0.06 \\
$\quad$ Agreeableness & $3.60(0.66)$ & $3.85(0.63)$ & 0.39 \\
$\quad$ Emotional Stability & $3.77(0.60)$ & $3.86(0.62)$ & 0.14 \\
Dehumanization outcomes & & & \\
$\quad$ Humanness & $3.34(0.57)$ & $3.47(0.57)$ & 0.21 \\
$\quad$ Human Nature & $3.47(0.65)$ & $3.56(0.64)$ & 0.15 \\
$\quad$ Human Uniqueness & $3.23(0.61)$ & $3.38(0.61)$ & 0.24 \\
Employment outcomes & & & \\
$\quad$ Worker suitability & $3.24(0.84)$ & $3.50(0.94)$ & 0.29 \\
$\quad$ Boss suitability & $2.82(0.92)$ & $2.84(0.97)$ & 0.03 \\
\hline Note. Possible mean scores on all outcomes ranged from 1 to 5. &
\end{tabular}

Extraversion $(r=.52)$, Agreeableness $(r=.30)$, and Emotional Stability $(r=.45)$. Two items assessed the perceived work competence of the character (i.e., "I felt like the person in the story would be a good employee/worker" and "I felt like the person in the story would be a good employer/boss"). These two items were analyzed individually. Four items concerned the denial of human nature (e.g., "I felt like the person in the story was mechanical and cold, like a robot") and four the denial of human uniqueness (e.g., "I felt like the person in the story lacked selfrestraint, like an animal"). In a departure from the preregistration, but in line with other work (Bastian, Denson, \& Haslam, 2013), the dehumanization were treated as a single scale as they only achieve adequate reliability when collapsed into a single scale $(\alpha=.81)$.

\section{Results}

Descriptive statistics for each condition and outcome are presented in Table 1. Analysis of participant evaluations with indicated that volunteering was associated with somewhat greater ratings of suitability as a worker $(d=0.29)$. The predicted effects of volunteering on Conscientiousness $(d=0.14)$ and humanness $(d=0.21)$ were smaller than expected, but volunteering did appear to increase perceived Agreeableness $(d=0.39)$. Only very small standardized mean differences between conditions were identified on the other measures.

\section{Discussion}

There was partial support for the a priori hypotheses in so far as volunteering improved perceptions of employability. However, this support was limited because volunteering only had very small effects on perceptions of Conscientiousness and humanness, although the differences were in the predicted direction. One unpredicted effect of volunteering emerged. Volunteering during periods of unemployment benefit receipt increased perceptions of a person's Agreeableness-a personality trait often thought to reflect interpersonal warmth (Digman, 1997; Wiggins, 1979, 1991). This could reflect that volunteering challenges the low warmth stereotype of welfare recipients (Bye et al., 2014; Fiske et al., 2002). Alternatively, this may reflect the effectiveness of the volunteering manipulation because Agreeableness captures characteristics like altruism and pro-sociality (Hilbig, Glöckner, \& Zettler, 2014).

We used vignettes to study the impact of volunteering because it allowed for precise experimental control over specific characteristics. This is advantageous for studying the isolated effects of a single factor in a way that cannot be done in a real-world setting. Pilot studies showed that respondents believed this specific unemployed benefit recipient vignette character should be volunteering and was stereotyped as low in Conscientiousness and humanness. One reason we may not have found full support for the hypotheses is that the character is already somewhat inconsistent with the stereotypic view of welfare recipients as "lazy" (Humpage, 2011; McKay, 2014; Schofield \& Butterworth, 2015). This relatively socially desirable characterization, with the exception of welfare receipt, may have created a relative ceiling effect in many of the evaluated traits. Examination of the volunteering effects with another, less socially desirable vignette character was required to rule out this possibility.

\section{Experiment 2}

Experiment 2 attempted to overcome the limitations identified in Experiment 1. This was achieved using a different vignette featuring a less socially desirable character. Moreover, by adding a currently employed condition, Experiment 2 sought to confirm the negative stereotypic perceptions of the unemployment benefit recipient and provide an anchor to quantify the volunteering effect (i.e., was a full or partial offset observed).

The development of the new vignette sought to prevent a spurious conclusion being drawn from the first experiment due to ceiling effects. As the character was rated positively despite his or her welfare receipt, volunteering may have been able to have only very small effects in the first experiment. It was predicted that the new character would be perceived as substantially less socially desirable than the character in the original vignette and thus have lower scores on all measured personality traits (Bäckström, Björklund, \& Larsson, 2009) and the other outcomes. Again, we tested the 
hypothesis that someone who was receiving unemployment benefits and volunteering would be perceived as more employable, Conscientious, and more human than someone who was receiving benefits but not volunteering. Despite finding that volunteering increased perceived Agreeableness in Experiment 1, no predictions were made for this outcome.

\section{Method}

\section{Sampling}

As noted in the preregistration, Experiment 2 followed up on two prior studies: Experiment 1 and a separate project examining the effect of rejecting welfare payments. This design decision was made due to overlapping reference conditions (employed, and unemployment benefits with new vignette). There were 701 complete data points obtained from the 640 advertised MTurk HITs. Seven of these individuals did not give consent for their data to be analyzed. Of the remaining 694, 660 came from IP addresses within the United States. Thirty-eight of these appeared to be duplicates based on IP addresses, leaving 622 first responses from each IP address. More participants than intended were allocated to the conditions relevant to the current experiment due to experimenter error in setting the formulas underpinning random allocation. We had planned to allocate 120 participants to each of the employed, unemployed and on benefits, and volunteering while on unemployment benefits conditions with the new vignette

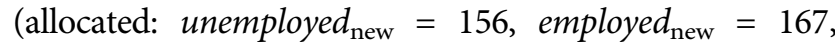
volunteering $_{\text {new }}=152$ ) and 40 to the unemployed and receiving benefits embedded in the old vignette (allocated: unemployed $_{\mathrm{old}}=58$ ).

\section{Participants}

The analyzed sample comprised 533 participants (224 female, 308 male, 1 other) from the United States recruited via MTurk. These participants had a mean age of $31.50(S D=9.96$, range $=18-66)$.

\section{Materials}

A single three-level between-person experimental manipulation randomly varied whether the character was described as on unemployed and receiving benefits, that is, "He is currently unemployed, and has been receiving government benefits for the last 6 months due to his unemployment"; volunteering while on benefits, that is, "He is currently unemployed but volunteers with a charity a few days every week, and has been receiving government benefits for the last 6 months due to his unemployment"; or employed, that is, "He is currently working as a sales assistant in a large department store." The vignette this was embedded within is presented next:

John is a 29 year old man who didn't finish school. [randomly varied condition text]. John is single and spends his evenings playing video games. This weekend a new strategy game he's been really looking forward to comes out. After purchasing the new game, he spent the whole of Sunday playing it before finally leaving the house to buy some Chinese takeaway for dinner.

The only feature that changed between the old and the new vignette was the described weekend activities. The new description of weekend activities is in line with increased use of leisure time to play video games among young, high school educated men (Aguiar, Bils, Charles, \& Hurst, 2017). Indeed, this representation is likely normative with $77 \%$ of young men playing video games and $33 \%$ identifying as gamers (Duggan, 2015). A small group of participants was allocated to the unemployed condition in the old vignette to confirm the effectiveness of the change in materials.

Vignette reading time was participant controlled; however, attention was confirmed via a free response comprehension test. The comprehension questions for the new vignette were "How old was the person in the story?" "What type of take-away did the person in the story buy?" and "What genre/type of game did the person in the story play?" The participants exposed to the old vignette were presented with the questions described in Experiment 1. Participants who incorrectly answered all three of the vignette comprehension questions were excluded from analysis $(n=$ 2). It was decided that there was no notable difference in the number of questions correct based on (un)employment condition $\left(\eta^{2}=.005\right)$ or in the vignette it was embedded within $\left(\eta^{2}=.001\right)$.

Preliminary analysis of the measures indicated that the items assessing Openness to Experience $(r=.25)$, Conscientiousness $(r=.58)$, Extraversion $(r=.20)$, Agreeableness $(r=.27)$, and Emotional Stability $(r=$ .38) were appropriately correlated with associations of at least a small size. Treating the dehumanization items as a single scale resulted in good internal consistency $(\alpha=.80)$, as in Experiment 1 .

\section{Results}

Descriptive statistics for all conditions are presented in Table 2. Comparisons of the new unemployed benefit recipient character to the old one indicated that they 
Table 2. By condition descriptive statistics breakdown on rated characteristics in Experiment 2.

\begin{tabular}{|c|c|c|c|c|}
\hline \multirow{2}{*}{$\begin{array}{l}\text { Vignette } \\
\text { Employment }\end{array}$} & \multirow{2}{*}{$\frac{\text { Old }}{\text { Unemployed } M(S D)}$} & \multicolumn{3}{|c|}{ New } \\
\hline & & Unemployed M (SD) & Volunteer $M(S D)$ & Employed $M(S D)$ \\
\hline$N$ & 58 & 156 & 152 & 167 \\
\hline \multicolumn{5}{|l|}{ Personality outcomes } \\
\hline Openness to Experience & $3.06(0.76)$ & $2.66(0.77)$ & $2.84(0.76)$ & $2.73(0.75)$ \\
\hline Conscientiousness & $3.42(0.67)$ & $2.23(0.78)$ & $2.63(0.86)$ & $2.92(0.84)$ \\
\hline Extraversion & $2.92(0.77)$ & $2.23(0.62)$ & $2.43(0.68)$ & $2.20(0.61)$ \\
\hline Agreeableness & $3.63(0.54)$ & $3.09(0.68)$ & $3.48(0.62)$ & $3.33(0.58)$ \\
\hline Emotional Stability & $3.73(0.54)$ & $3.13(0.72)$ & $3.37(0.67)$ & $3.44(0.65)$ \\
\hline \multicolumn{5}{|l|}{ Dehumanization outcomes } \\
\hline Humanness & $3.42(0.43)$ & $2.71(0.62)$ & $3.00(0.57)$ & $2.95(0.58)$ \\
\hline Human Nature & $3.53(0.48)$ & $2.85(0.66)$ & $3.17(0.65)$ & $2.99(0.61)$ \\
\hline Human Uniqueness & $3.31(0.52)$ & $2.57(0.71)$ & $2.84(0.66)$ & $2.90(0.70)$ \\
\hline \multicolumn{5}{|l|}{ Employment outcomes } \\
\hline Worker suitability & $3.31(0.75)$ & $2.33(0.94)$ & $2.75(0.95)$ & $3.28(0.91)$ \\
\hline Boss suitability & $2.78(0.82)$ & $2.00(0.83)$ & $2.38(0.95)$ & $2.69(0.90)$ \\
\hline
\end{tabular}

Note. Possible mean scores on all outcomes ranged from 1 to 5 .

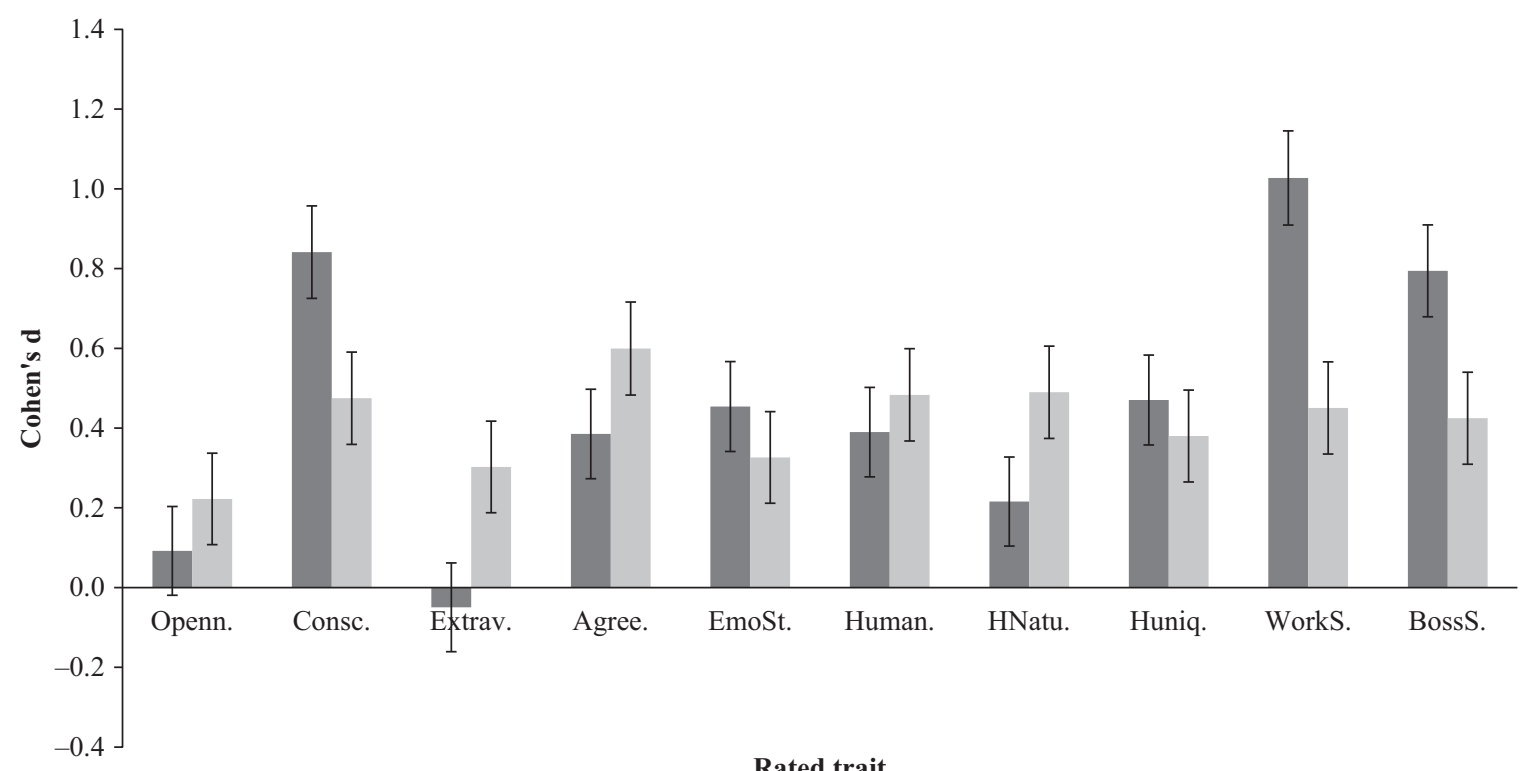

Rated trait

Effect of employment (employed vs. unemployed; i.e., welfare stigma) $\quad$ Effect of volunteering (volunteering vs. unemployed)

Figure 1. Effects of volunteering and employment on evaluated traits relative to unemployed and on benefits. Note. Error bars denote \pm 1 SE of Cohen's $d$. Openn.: Openness to Experience; Consc.: Conscientiousness; Extrav.: Extraversion; Agree.: Agreeableness; EmoSt.: Emotional Stability; Human.: humanness; HNatu.: human nature; HUniq.: human uniqueness; WorkS.: worker suitability; BossS: boss suitability.

were rated less positively on all outcomes. The character in the new vignette was rated as less Open $(d=-0.52)$, Conscientious $(d=-1.58)$, Extraverted $(d=-1.05)$, Agreeable $(d=-0.84)$, Emotionally Stable $(d=-0.89)$, human $(d=-1.22)$, suitable as a worker $(d=-1.10)$, and suitable as a boss $(d=-0.93)$.

Figure 1 shows that volunteering while receiving unemployment benefits was associated with more positive ratings on all measured dimensions compared to receipt of unemployment benefits. Employment was also associated with more positive ratings relative to receipt of unemployment benefits for many outcomes $(d s \geq 0.39)$, but there was no evidence of more positive Extraversion or Openness to Experience ratings $(|d s| \leq 0.09)$. To assess the relative magnitude of volunteering and employment effects, the difference between volunteering and not volunteering among unemployment benefit recipients (volunteering effect) was compared to the difference between unemployment benefit receipt and employment among volunteers (welfare effect). Employment had a greater effect than volunteering for ratings of Conscientiousness, worker suitability and boss suitability; employment 
and volunteering had comparably sized effects on Emotional Stability and humanness; and the effect of volunteering was greater than that of employment on ratings of Extraversion and Agreeableness.

\section{Discussion}

The effects of volunteering on all outcomes were in the same direction across Experiments 1 and 2. The small-to-medium-sized effects of volunteering on Agreeableness and worker suitability seen in Experiment $1(d=0.39)$ were larger in Experiment 2 $(d=0.60)$. Moreover, at least a small size effect (i.e., $d$ $\geq 0.2$ ) of volunteering while in receipt of welfare was now present on all outcomes, including the hypothesized effects on Conscientiousness $(d=0.47)$, humanness $(d=0.48)$, and worker suitability $(d=0.45)$. The positive effects of volunteering and the negative effects of welfare receipt affected the same outcome dimensions. Volunteering thus appears to counteract the negative perceptions of traits that characterize welfare recipients. This could be because volunteering is a worklike behavior, or because volunteering displays reciprocity and social connectedness. If volunteering serves only to display a capacity for work, then its effects should be confined to the welfare recipient group because employed individuals have already displayed their capacity to work. By contrast, employed and unemployed individuals alike can display reciprocity and social connection by volunteering. Thus, if reciprocity is the mechanism, perceptions of both employed individuals and welfare recipients should benefit from volunteering. This can be tested by examining whether volunteering affects workers and welfare recipients equally. The fact that volunteering had some effects that exceeded those of benefit receipt (e.g., on Agreeableness) in Experiment 2 suggests that it probably influences perceptions beyond the capacity for worklike behavior.

In a context where volunteering was hypothesized to increase perceptions of employability, Conscientiousness and humanness, we proposed the failure to find large experimental effects on Conscientiousness and humanness evaluations in Experiment 1 may have reflected the presence of ceiling effects tied to the general positivity of the materials used. We argued that decreasing the overall desirability of the vignette character may enable detection of the predicted effects. Experiment 2 reduced the positive perceptions of the character and found the predicted effects. The new vignette character was perceived as less positively on all measured traits linked to social desirability than the character in the previous vignette. Critically, improvements in perceived character from volunteering were evident for a greater range of predicted characteristics with the new character. We speculated that the new stimuli would elicit the hypothesized effects by lowering social desirability and preventing ceiling effects, but it might have also been contingent on how social desirability was lowered. The character in Experiment 2 was described not only as generally less socially desirable but specifically as spending "public money" on non-essential items (e.g., video games, take-away food). It is possible that this description of spending on non-essential, which might be seen as inappropriate by some members of the community, was necessary to elicit the improved evaluations from volunteering.

\section{Experiment 3}

Experiment 3 tested two outstanding questions. First, does volunteering lead to improved perceptions of all people-irrespective of whether they are receiving government benefits or workers-or are the improvements confined to unemployed welfare recipients for whom volunteering may serve as a proxy for paid employment? Second, are the negative perceptions of welfare recipients attributable to or exacerbated by the expenditure of welfare benefits on non-essential purchases? Such behavior is one potential behavioral mechanism that could explain the evaluative stigma associated with receiving unemployment benefits.

For these research questions we again focused on the dimensions of Conscientiousness, humanness, employability considered a priori in Experiments 1 and 2. Moreover, as volunteering increased Agreeableness ratings in both Experiments 1 and 2, we predicted this to be the main dimension affected by volunteering. We made no specific decision about which of the competing hypotheses we expected the data to support in either the welfare by volunteering analysis or the welfare by spending behavior analysis.

\section{Method}

\section{Sampling}

Complete responses were received from 969 individuals in response to the 960 advertised MTurk HITs, again, with a target of 120 per condition. Eleven of these did not provide consent for their data to be analyzed, and one other was younger than 18. Of the 
remaining 954, 19 appeared to be duplicates based on IP addresses, leaving 935 first responses from each IP address. In a departure from preregistered plans, one additional subject was removed, as they wrote the same experiment irrelevant comment in every text box.

\section{Participants}

The analyzed sample comprised 934 participants (573 female; 357 male; 1 intersex; 1 other, non-binary; 2 prefer not to say) from the United States recruited via MTurk. These participants had a mean age of 37.65 $(S D=12.68$, range $=18-89$; one prefer not to say $)$.

\section{Materials}

The description of the character was manipulated using a 2 (employment: unemployment benefits vs. employed) $\times 2$ (volunteering: volunteer vs. nonvolunteering) $\times 2$ (spending: non-essentials vs. essentials) between-person experimental design:

John is a 29 year old man who didn't finish school. [employment and volunteering text]. John is single and spends his evenings playing video games. This weekend a new strategy game he's been really looking forward to comes out. [spending text \#1] he spent the whole of Sunday playing it before finally leaving the house to buy [spending text \#2].

The text denoting employment and unemployment benefits was identical to the two prior studies. Those in the volunteering condition had an additional clause (noted in italics, but presented without italics) embedded in the employment text such that it read, "He is currently unemployed, [and] has been receiving government benefits for 6 months due to his unemployment, and does volunteer work in the community for 8 hours each week" or "He is currently working as a sales assistant in a large department store, and does volunteer work in the community for 8 hours each week." Those in the non-volunteering conditions simply had this omitted. The first section of spending text indicated that either the character purchased the game (non-essentials: "After purchasing the new game,) or was gifted the game (essentials: "A friend bought him a copy of the new game, and"); the second section indicated either a more (non-essentials: Chinese take-away with a friend for dinner") or less (essentials: "groceries for dinner") expensive dinner option. The non-essentials condition is thus a revision of the vignette used in Experiment 2 with sociability equated, that is, both levels of the factor made one reference to the character's friend.
Table 3. Descriptive statistics for rated characteristics in Experiment 3, and correlations between these rated characteristics.

\begin{tabular}{lcccccccr}
\hline & & \multicolumn{1}{c}{ Correlations between outcomes } \\
\cline { 3 - 9 } Outcomes & $M(S D)$ & 1 & 2 & 3 & 4 & 5 & 6 & 7 \\
\hline 1. Openness & $2.44(0.74)$ & & & & & & & \\
2. Conscientiousness & $2.72(1.03)$ & 0.15 & & & & & & \\
3. Extraversion & $2.77(0.82)$ & 0.32 & 0.44 & & & & & \\
4. Agreeableness & $3.43(0.70)$ & 0.10 & 0.55 & 0.37 & & & & \\
5. Emotional Stability & $3.44(0.73)$ & 0.10 & 0.51 & 0.26 & 0.55 & & & \\
6. Humanness & $2.98(0.69)$ & 0.22 & 0.76 & 0.61 & 0.64 & 0.52 & & \\
7. Worker Suitability & $2.90(1.12)$ & 0.05 & 0.74 & 0.37 & 0.54 & 0.46 & 0.70 & \\
8. Boss Suitability & $2.43(1.02)$ & 0.17 & 0.69 & 0.42 & 0.45 & 0.39 & 0.67 & 0.69 \\
\hline
\end{tabular}

Vignette reading time was again participant controlled with a free response comprehension test. The comprehension questions were "How old was the person in the story?" "Which meal of the day did the person leave the house for?" "What genre/type of game did the person in the story play?" Participants who incorrectly answered all three vignette comprehension questions were excluded from analysis $(n=16) .{ }^{4}$ Based on the inspection of means, there was little evidence that the average number of correct questions differed across levels of each condition (unemployment benefits vs. employed, $d=0.02$; volunteer vs. non-volunteering, $d=0.02$; non-essentials vs essentials, $d=0.05$ ).

Preliminary analysis of the measures indicated that the items assessing Openness to Experience $(r=0.33)$, Conscientiousness $(r=0.64)$, Extraversion $(r=0.36)$, Agreeableness $(r=0.29)$, and Emotional Stability $(r=0.43)$ were appropriately correlated. Treating the dehumanization items as a single scale resulted in good internal consistency $(\alpha=0.84)$, as in Experiments 1 and 2 . The descriptive statistics for each measure and the correlations between them are reported in Table 3.

\section{Analysis}

Bivariate associations of each manipulated factor with each outcome dimension were first considered, and these were followed by a series of multiple regression models. Model 1 considered the effect of the three main effects simultaneously. Model 2 added the unemployment benefits by volunteering interaction to the three main effects, whereas Model 3 added the welfare by spending interaction to the three main effects. Model 4 considered all three two-way interactions, whereas Model 5 added the three-way interaction between unemployment benefits, volunteering, and spending. 
Table 4. Cohen's $d$ associated with bivariate analyses and multiple regression analyses (with only the highest-level effects in each model reported).

\begin{tabular}{|c|c|c|c|c|c|c|c|c|c|c|c|c|}
\hline \multirow[b]{3}{*}{ Outcomes } & & & & \multicolumn{9}{|c|}{ Multiple regression models } \\
\hline & \multicolumn{3}{|c|}{ Bivariate associations } & \multicolumn{3}{|c|}{ Model 1} & \multirow{2}{*}{$\frac{\text { Model } 2}{U \times V}$} & \multirow{2}{*}{$\frac{\text { Model } 3}{U \times N}$} & \multicolumn{3}{|c|}{ Model 4} & \multirow{2}{*}{$\frac{\text { Model } 5}{\mathrm{U} \times \mathrm{V} \times \mathrm{N}}$} \\
\hline & $\mathrm{U}$ & V & $\mathrm{N}$ & $\mathrm{U}$ & V & $\mathrm{N}$ & & & $\mathrm{U} \times \mathrm{V}$ & $\mathrm{U} \times \mathrm{N}$ & $\mathrm{V} \times \mathrm{N}$ & \\
\hline Openness to Experience & 0.20 & 0.06 & 0.22 & 0.20 & 0.06 & 0.21 & -0.09 & 0.13 & -0.09 & 0.13 & -0.18 & 0.12 \\
\hline Conscientiousness & -1.05 & 0.36 & 0.04 & -1.05 & 0.34 & 0.05 & -0.15 & -0.09 & -0.15 & -0.08 & 0.00 & -0.12 \\
\hline Extraversion & -0.21 & 0.24 & -0.07 & -0.21 & 0.24 & -0.08 & -0.05 & 0.06 & -0.06 & 0.07 & 0.03 & -0.09 \\
\hline Agreeableness & -0.64 & 0.48 & -0.01 & -0.64 & 0.47 & -0.01 & 0.05 & -0.09 & 0.05 & -0.09 & -0.06 & -0.09 \\
\hline Emotional Stability & -0.61 & 0.37 & -0.07 & -0.60 & 0.36 & -0.07 & -0.04 & -0.16 & -0.04 & -0.16 & 0.07 & -0.20 \\
\hline Humanness & -0.69 & 0.41 & 0.02 & -0.68 & 0.40 & 0.03 & -0.04 & -0.02 & -0.04 & -0.02 & 0.06 & -0.06 \\
\hline Worker Suitability & -1.22 & 0.31 & -0.11 & -1.21 & 0.30 & -0.10 & -0.09 & -0.07 & -0.09 & -0.06 & 0.09 & -0.09 \\
\hline Boss Suitability & -0.87 & 0.30 & -0.01 & -0.86 & 0.29 & -0.01 & -0.14 & -0.06 & -0.14 & -0.06 & 0.02 & 0.09 \\
\hline
\end{tabular}

Note. Cohen's $d$ is reported for consistency with prior studies and was calculated from the standardized beta coefficient in multiple regression as $d=\frac{2 \beta}{\sqrt{1-\beta^{2}}}$. $\mathrm{U}=$ unemployment benefits (vs. employed); $\mathrm{V}=$ volunteering (vs. not volunteering); $\mathrm{N}=$ spending on non-essentials (vs. essentials).

\section{Results}

There were clear bivariate effects of receiving unemployment benefits and volunteering on evaluations of most character traits (Table 4). As in Experiment 2, the large associations between receiving unemployment benefits and being judged as low in Conscientiousness, and as poor workers and bosses, were replicated; so too were the medium-sized effects on low Agreeableness, Emotional Stability, and humanness ratings. The small-to-medium sized effects $(0.30<d s \leq 0.48)$ of volunteering on all outcomes except Openness to Experience in Experiment 2 were also replicated in the current study. There were somewhat higher Openness to Experience ratings $(d=$ 0.22 ) among those described as spending money on non-essentials, but the differences on ratings of other characteristics had standardized mean differences that were trivially small, especially against the backdrop of larger effects of other factors. Consistent with the use of a factorial design, adjusting for the other main effects in Model 1 had little effect on Cohen's $d$ for unemployment benefit receipt, volunteering, or spending on any outcome, all $\left|\Delta_{\mathrm{d}}\right| \mathrm{s} \leq 0.01$.

Where Experiment 2 had examined only the effect of volunteering in the unemployment benefit recipient group, Model 2 of Experiment 3 considered the interaction between receiving benefits and volunteering (Figure 2). The difference in effect of volunteering in the unemployment benefits and employed groups were very small, with the welfare by volunteering interactions having $|d| s \leq 0.15$. This conclusion did not change when the other two-way interactions were added in Model $4(|d| s \leq 0.15)$. This pattern of results suggests that receiving benefits and volunteering are best characterized as two independent main effects on perceptions of character and are unlikely to have even small-size conditional effects.
Model 3 added the interaction between unemployment benefit receipt and spending behavior. The analyses suggested that spending money on non-essentials (as in the Experiment 2 vignette) is unlikely to explain why welfare recipients are evaluated more negatively than the employed. All interactions were of a very small size, with the welfare by spending interactions having $|d| s \leq 0.16$. This did not change when the other two-way interactions were added in Model 4 $(|d| \mathrm{s} \leq 0.16)$.

Finally, the three-way interactions added in Model 5 were also very small for each outcome, with all $|d| s$ $<0.20$.

\section{Discussion}

The effects in Experiment 3 were confined to two of the three manipulated characteristics: volunteering and welfare receipt. Volunteering compared to nonvolunteering was associated with greater perceived levels of all characteristics except Openness to Experience. Unemployment benefit receipt compared to employment, by contrast, was associated with substantially lower ratings of Conscientiousness, and worker and boss suitability, and as somewhat lacking in Agreeableness, Emotional Stability, and humanness. The critical tests of the interaction between welfare receipt and volunteering indicated that volunteering had similar effects on benefit recipients and the employed. This pattern of results suggests that volunteering leads to more positive ratings of benefit recipients, not because it communicates a capacity for worklike behavior that is otherwise absent among unemployed benefit recipients but through some other pathway (e.g., displaying reciprocity). Finally, we did not find any effects of spending money on nonessentials at a size that indicated that spending behavior substantially altered perceptions of any characters, 

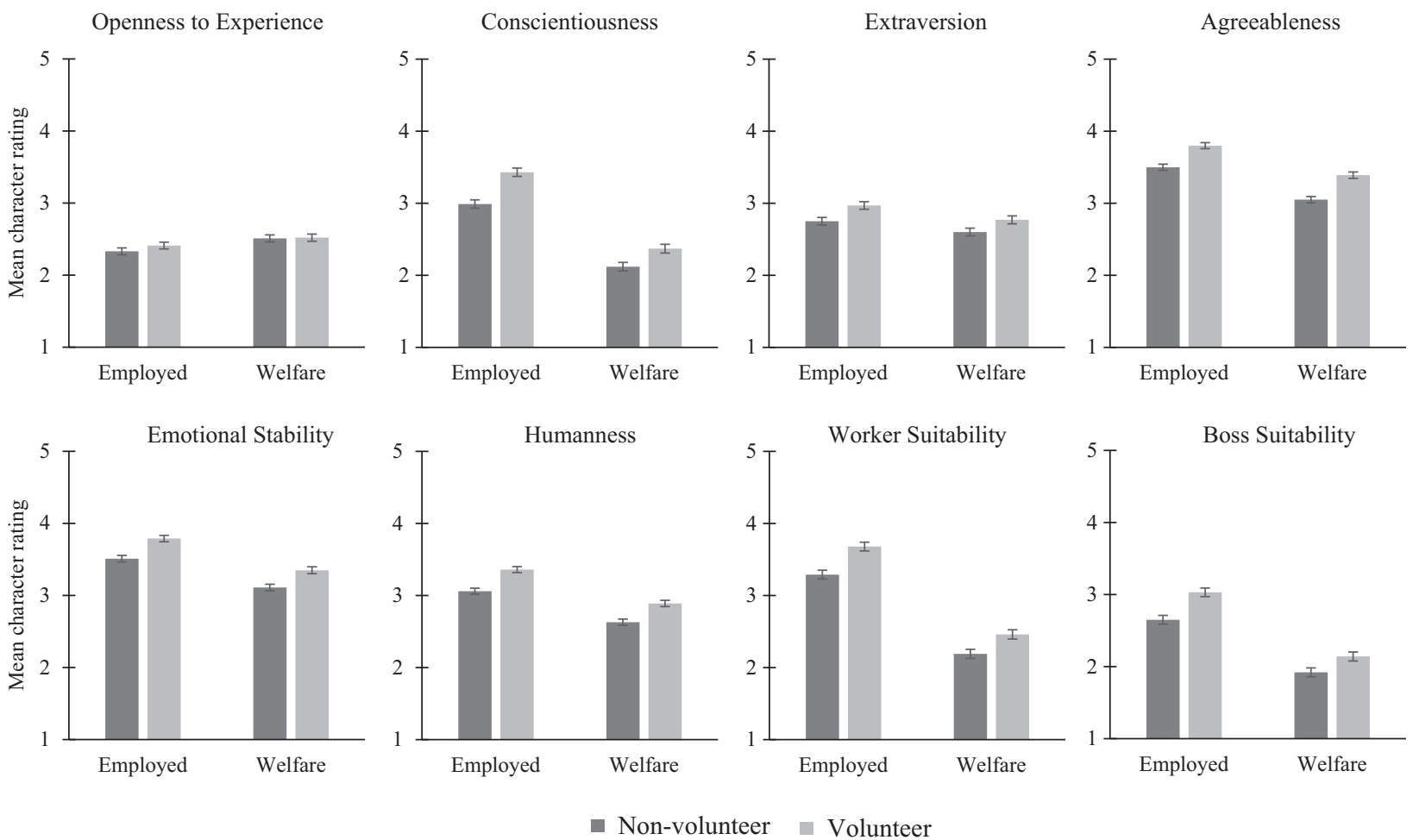

Figure 2. Plot of the marginal $2 \times 2$ relationship between welfare receipt and volunteering in Experiment 3 . Note. There does not appear to be any evidence of interactive effects on any outcome, with main effects of both welfare and volunteering evident for all outcomes except Openness to Experience. Error bars denote $\pm 1 \mathrm{SE}$.

including the unemployed benefit recipients. Thus, despite public concerns about the spending behavior of people who rely on the welfare system for support, it does not appear to be the mechanism responsible for the negative evaluations of unemployed benefit recipients, nor can it account for the larger effects of volunteering in Experiment 2 than Experiment 1.

\section{General discussion}

Mutual obligation requirements, such as volunteering, are a hallmark of modern welfare policies. They are endorsed by the general public (Humpage, 2011; Saunders, 2002; Schofield \& Butterworth, 2015; Shapiro et al., 1987; Van Oorschot, 1998) and seen as tools of empowerment by politicians (e.g., Abetz, 2014; McClure et al., 2015). Across three experiments we found patterns of differences indicating consistent evidence that unemployed benefit recipients engaged in volunteering activities are perceived more positively and seen as more employable than unemployed recipients of who do not volunteer. These results suggest that members of typically stigmatized groups can be perceived more favorably if they volunteer. The observed effect is consistent with employer (vinspired, 2008) and community beliefs (e.g., pilot data) that volunteering while receiving benefits will help welfare recipients and potentially increase their employability. However, this effect was also observed for those who were already in paid employment, which suggested that the benefits of volunteering are not simply because it increases human capital (i.e., useful work skills) among those lacking these characteristics. Overall, volunteering did not disproportionately improve perceptions of recipients of unemployment benefits. This pattern of results is more consistent with the hypothesis that volunteering improves perceptions because it demonstrates a willingness to give something back to the community. It may be tempting to label the observed effects of volunteering on evaluations evidence of a halo effect (Thorndike, 1920). Despite being similar, a halo effect explanation is not supported because volunteering did not affect all dimensions; the observed effects provided little evidence that volunteering increased socially desirable Openness to Experience ratings $(d s=0.00,0.22,0.06$; Bäckström et al., 2009). Thus, there is likely some specificity to the effects of volunteering on perception of character.

Volunteering improved the perceptions of welfare recipients, challenging and counteracting the negative community perceptions of people who are receiving 
unemployment benefits. These new findings complement existing research on the effect of volunteering on the employment outcomes of welfare recipients. Volunteering had pronounced effects on the perceptions of the Conscientiousness, worker suitability, boss suitability, and humanness of unemployment benefit recipients. Not only are these the same traits that were rated as lacking among the recipients of unemployment benefits, but they are also traits clearly linked to stigmatization (Harris \& Fiske, 2011) and workplace success (Barrick et al., 2001). Volunteering-and making this activity known to potential employers-can alleviate some of the disadvantage welfare recipients experience in the job market by challenging stereotypes of their character. Volunteering compensated for approximately $25 \%-50 \%$ of the standardized mean difference in the negative evaluations of welfare recipients' Conscientiousness and worker and boss suitability. These findings have important implications for how individual job seekers present themselves, and for the community and for-profit organization assisting job seekers. Of course, further research is needed, including research showing that the current results generalize from a broad community sample to those within the community who make hiring decisions.

A much greater compensatory effect of volunteering was present for perceptions of humanness (approximately $60 \%-80 \%$ of the standardized mean difference in the evaluation of the employed compared to unemployed). Dehumanization leads to the social exclusion and mistreatment of stigmatized groups by others (Bandura, Underwood, \& Fromson, 1975; Bastian et al., 2013). As such, it is notable that community members' perceptions of welfare recipient humanness were substantially improved by volunteering as this may provide a mechanism to foster more positive social outcomes for people otherwise stigmatized because of their welfare receipt. Volunteering also increased perceptions of Emotional Stability, Agreeableness, and Extraversion, which were seen as somewhat lower among recipients of unemployment benefits. This is a similar trait profile to that reported by volunteers (Carlo, Okun, Knight, \& de Guzman, 2005; Pearce, 1993). Not only might disclosing volunteering to employers be advisable, but it may be advantageous to welfare recipients to disclose their volunteering in their social circles to prevent dehumanization.

The current studies provide evidence of the potential benefits of including volunteering as a component of welfare policy and employment assistance programs. Previous investigations have shown mixed evidence of volunteering style activities affecting employment outcomes (Gay, 1998; Kamerāde \& Paine, 2014; Kellard et al., 2015; Konstam et al., 2015; Spera et al., 2015; vinspired, 2008; Warburton \& Smith, 2003), but these studies have not considered how community perceptions of welfare recipients might have changed. However, it is possible that potential employers are less influenced in their employment decisions by perceptions of character, stigma (i.e., less dehumanized), and soft skills (i.e., seen as good workers) but focus more on job-specific hard skills. Nonetheless, the current results may indicate that the moderate efficacy of training and skillbased welfare programs for the long-term unemployed could be enhanced through the addition of a volunteering component (Greenberg, Ashworth, Cebulla, \& Walker, 2004). The core challenge for policymakers will be designing these programs so that they continue to meet community expectations about mutual obligations (McClure et al., 2015) without detracting from the ability of unemployed welfare recipients to search for work (Borland \& Tseng, 2011). The current studies provide some evidence of the potential benefits of volunteering as an element of welfare policy and employment assistance programs.

Consistent with prior work in this domain, providing individual information inconsistent with a welfare stereotype can overwhelm stereotypic evaluations (Aar $\oslash \mathrm{e} \&$ Petersen, 2014). Highlighting engagement in community activities may be one way for individuals to challenge and avoid being perceived as a stereotypical recipient of unemployment benefits. The current experiments have considered only recipients of unemployment benefits, and future work should consider the generalizability of the patterns of results to other characteristics and categories of payment. Other studies have reported similar effects of volunteering for unemployed characters not receiving welfare benefits (Shore \& Tashchian, 2013). Here we demonstrated that even when adding the stigmatized characteristic of welfare receipt to unemployment, volunteering can promote more positive perceptions of a person's character. Even groups of individuals already seen as deserving of support, such as those receiving an Age Pension or Carer Payment (Van Oorschot, 2000), are likely to be perceived more positively if they are engaged in volunteering, just as employed individuals benefited here. Although we found volunteering effects for welfare recipients and nonrecipients alike, it is important to continue the applied study of volunteering in the context of welfare recipients. A circumstance unique to welfare recipients is "mandated" volunteering, and it is unclear whether 
the effects observed in these samples will generalize to that case. Future work should investigate whether community work has to be truly voluntary to improve perceptions of character, or whether mandated activity to satisfy mutual obligations requirements is also perceived as favorably (Morehead \& Griff, 1996; Warburton \& Smith, 2003).

Vignette-based person perception methods have been used in many contexts, but their application to assessing the impacts of social welfare policy is relatively novel. This is somewhat surprising given claims that community perceptions, attitudes, and expectations should be an important driver of social policy (e.g., McClure et al., 2015). The methods allow modeling of the impact of proposed social policy changes through experimental manipulation of policy-relevant characteristics and observing the effect that this has on perceptions and evaluations. This style of investigation provides a cost-effective approach to evaluation prior to program rollout. Future work should consider whether the effect of volunteering on perceived character is conditional on the sociodemographic characteristics of the target. The cross-study differences in the present work suggested that volunteering is likely to be more advantageous to individuals perceived as less socially desirable (perhaps reflecting ceiling effects), but prior work in the welfare domain shows little evidence of interactions with sociodemographic characteristics (Kootstra, 2016). This understanding will be important when tailoring mutual obligation requirements to the individual. In the present case, the novel use of experimental methods allowed testing of whether volunteering reduced stigmatizing views of welfare recipients that may be a barrier to positive employment outcomes. We found evidence that volunteering compensates for, but does not prevent, the negative stereotyping of individuals receiving unemployment benefits. However, other forms of mutual obligation activities exist and should be similarly considered. Future work using these methodologies could consider whether participation in hard-skill-oriented volunteering (e.g., industry-specific "internship" programs), more general community participation (e.g., Australia: Youth Jobs PaTH; Ireland: JobBridge), or enrollment in formal education and training programs have differential effects on community perceptions and stereotypes of welfare recipients.

\section{Contributions}

TPS PB conceived and designed the studies, TPS conducted the experiments, TPS PB analyzed the data.
TPS PB wrote and edited and approved the manuscript. The studies are conducted in the order they appear.

\section{Author note}

All experiments were preregistered, and all deviations from the preregistration are noted in text. All deidentified and analyzed raw data, analysis scripts, and preregistrations are available via the OSF (https://doi.org/10.17605/OSF.IO/ F3EM6). The relevant materials and data underpinning the pilot analyses are also reported here.

\section{Funding}

This paper was funded by the Australian Research Council (ARC) grant \#DP160104178 awarded to $\mathrm{PB}$, and $\mathrm{PB}$ is funded by an ARC Future Fellowship \#FT13101444 and also a "University of Melbourne Faculty of Medicine, Dentistry and Health Sciences Research Fellowship".

\section{Notes}

1. Two other hypotheses were preregistered. One was that the associations between worker suitability and Conscientiousness and humanness would be greater in the welfare than volunteering condition. This was anticipated, as we assumed that perceived Conscientiousness would be used as a marker of employability more for people who were not working than those who were. Interactions between condition and trait (Conscientiousness, humanness) revealed little evidence of an interaction in this sample. The second were a set of mediation analyses, which are omitted as a result of questions about their suitability raised during peer review. Such analyses are also omitted from Experiment 2.

2. Cohen's $d$ represents the standardized mean difference between the two groups. Assuming the ratings within each condition are both normally distributed, the probability that a randomly selected rating of the character volunteering while on unemployment benefits is higher than a randomly selected rating of the unemployed character receiving benefits is $50 \%$ at $d=0.00,56 \%$ at $d=0.20$ (often called small), $64 \%$ at $d=0.50$ (medium), $72 \%$ at $d=0.80$ (large), and $80 \%$ at $d=1.20$ (McGraw \& Wong, 1992). A medium effect is often reported as noticeable.

3. Consistent with journal policy, the preregistered decision to use $p$-values to make this decision was not followed. The observed effects of condition on comprehension were very small, and substantially smaller than all effects interpreted as providing support for the hypotheses.

4. This includes one participant who skipped all three questions prior to responses being made required for these questions; no other participants missed any questions. 


\section{ORCID}

Timothy P. Schofield (D) http://orcid.org/0000-00020357-9607

Peter Butterworth (D) http://orcid.org/0000-0002-1531-3881

\section{References}

Aarøe, L., \& Petersen, M. B. (2014). Crowding out culture: Scandinavians and Americans agree on social welfare in the face of deservingness cues. The Journal of Politics, 76, 684-697. doi:10.1017/S002238161400019X

Abetz, E. (2014). New Senate; new employment programmes/ Interview: A. Carabine. [Transcript]. ABC Radio National. Retreived from https://ministers.jobs.gov.au/abetz/interviewalison-carabine-abc-radio-national

Aguiar, M., Bils, M., Charles, K., \& Hurst, E. (2017). Leisure Luxuries and the Labor Supply of Young Men. National Bureau of Economic Research Working Paper No. 23552. Retrieved from https://www.nber.org/papers/w23552.pdf

Australian Bureau of Statistics. (2016). 6227.0 - Education and Work, Australia, May 2016. Retrieved from http:// archive.is/PjEUC

Bäckström, M., Björklund, F., \& Larsson, M. R. (2009). Five-factor inventories have a major general factor related to social desirability which can be reduced by framing items neutrally. Journal of Research in Personality, 43, 335-344. doi:10.1016/j.jrp.2008.12.013

Bandura, A., Underwood, B., \& Fromson, M. E. (1975). Disinhibition of aggression through diffusion of responsibility and dehumanization of victims. Journal of Research in Personality, 9, 253-269. doi:10.1016/0092-6566(75) 90001-X

Barrick, M. R., Mount, M. K., \& Judge, T. A. (2001). Personality and performance at the beginning of the new millennium: What do we know and where do we go next? International Journal of Selection and Assessment, 9, 9-30. doi:10.1111/1468-2389.00160

Bastian, B., Denson, T. F., \& Haslam, N. (2013). The roles of dehumanization and moral outrage in retributive justice. PLoS One, 8, e61842 doi:10.1371/journal.pone.0061842

Borland, J., \& Tseng, Y.-P. (2011). Does 'Work for the Dole'work?: An Australian perspective on work experience programmes. Applied Economics, 43, 4353-4368. doi:10.1080/00036846.2010.491457

Boyce, C. J., Wood, A. M., Daly, M., \& Sedikides, C. (2015). Personality change following unemployment. Journal of Applied Psychology, 100, 991-1011.

Bruttel, O., \& Sol, E. (2006). Work first as a European model? Evidence from Germany and the Netherlands. Policy \& Politics, 34, 69-89. doi:10.1332/030557306775 212142

Bureau of Labor Statistics. (2017). E-16. Unemployment rates by age, sex, race, and Hispanic or Latino ethnicity. Labor Force Statistics from the Current Population Survey. Retrieved from http://archive.is/tQYeW

Bye, H. H., Herrebrøden, H., Hjetland, G. J., Røyset, G. Ø., \& Westby, L. L. (2014). Stereotypes of Norwegian social groups. Scandinavian Journal of Psychology, 55, 469-476. doi:10.1111/sjop.12141
Carlo, G., Okun, M. A., Knight, G. P., \& de Guzman, M. R. T. (2005). The interplay of traits and motives on volunteering: Agreeableness, extraversion and prosocial value motivation. Personality and Individual Differences, 38(6), 1293-1305. doi:10.1016/j.paid.2004.08.012

Clary, E. G., \& Snyder, M. (1999). The motivations to volunteer: theoretical and practical considerations. Current Directions in Psychological Science, 8, 156-159. doi:10.1111/1467-8721.00037

Cook, P., \& Jackson, N. (2006). Valuing volunteering. A Route to Professional Development: Views from VSO Volunteers and Managers. London: Chartered Management Institute.

Cordingley, S. (1997). Unemployment and volunteering. Australian Journal on Volunteering, 2, 4-8.

Crisp, R., \& Fletcher, D. R. (2008). A comparative review of workfare programmes in the United States, Canada and Australia (No. 533). London: Department for Work and Pensions.

Digman, J. M. (1997). Higher-order factors of the Big Five. Journal of Personality and Social Psychology, 73, 1246-1256. doi:10.1037/0022-3514.73.6.1246

Department of Social Services. (2016). 1.1.M.160 Mutual obligation requirements. In Guide to Social Security Law, Version 1.226 - Released 4 October 2016. http://guides. dss.gov.au/guide-social-security-law/1/1/m/160.

Duggan, M. (2015). Gaming and gamers. Pew Research Center. Retried from http://www.pewinternet.org/2015/ 12/15/gaming-and-gamers/

Fiske, S. T., Cuddy, A. J., Glick, P., \& Xu, J. (2002). A model of (often mixed) stereotype content: competence and warmth respectively follow from perceived status and competition. Journal of Personality and Social Psychology, 82, 878-902. doi:10.1037//0022-3514.82.6.878

Gay, P. (1998). Getting into work: Volunteering for employability. Voluntary Action, 1, 55-67.

Gosling, S. D., Rentfrow, P. J., \& Swann, W. B. (2003). A very brief measure of the Big-Five personality domains. Journal of Research in Personality, 37, 504-528. doi:10.1016/S0092-6566(03)00046-1

Greenberg, D., Ashworth, K., Cebulla, A., \& Walker, R. (2004). Do welfare-to-work programmes work for long? Fiscal Studies, 25, 27-53. doi:10.1111/j.14755890.2004.tb00095.x

Harris, L. T., \& Fiske, S. T. (2011). Dehumanized perception: A psychological means to facilitate atrocities, torture, and genocide? Zeitschrift Für Psychologie, 219, 175-181. doi:10.1027/2151-2604/a000065

Hilbig, B. E., Glöckner, A., \& Zettler, I. (2014). Personality and prosocial behavior: Linking basic traits and social value orientations. Journal of Personality and Social Psychology, 107, 529. doi:10.1037/a0036074

Houle, B. J., Sagarin, B. J., \& Kaplan, M. F. (2005). A functional approach to volunteerism: Do volunteer motives predict task preference? Basic and Applied Social Psychology, 27, 337-344. doi:10.1207/s15324834basp2704_6

Humpage, L. (2011). What do New Zealanders think about welfare. Policy Quarterly, 7, 8-13.

Independent Sector. (2001). Giving and volunteering in the United States: Key findings. Retrieved from http://www. independentsector.org/programs/research/gv01main.html. 
Ironmonger, D. (1998). Measuring the dollar value of volunteering. Australian Journal on Volunteering, 3, 19-24.

Kamerāde, D., \& Paine, A. E. (2014). Volunteering and employability: Implications for policy and practice. Voluntary Sector Review, 5, 259-273. doi:10.1332/ $204080514 X 14013593888736$

Kellard, K., Honey, N., McNamara, T., Biddle, N., \& Gray, M. (2015). Evaluation of work for the dole 2014-15. Retrieved from https://docs.jobs.gov.au/system/files/doc/other/evaluation_of_work_for_the_dole_2014-15_accessible_final.pdf

Konstam, V., Tomek, S., Celen-Demirtas, S., \& Sweeney, K. (2015). Volunteering and reemployment status in unemployed emerging adults a time-worthy investment? Journal of Career Assessment, 23, 152-165. doi:10.1177/ 1069072714523248

Kootstra, A. (2016). Deserving and undeserving welfare claimants in Britain and the Netherlands: Examining the role of ethnicity and migration status using a vignette experiment. European Sociological Review, 32, 325-338. doi:10.1093/esr/jcw010

Laker, D. R., \& Powell, J. L. (2011). The differences between hard and soft skills and their relative impact on training transfer. Human Resource Development Quarterly, 22, 111-122. doi:10.1002/hrdq.20063

McClure, P., Sinclair, S., \& Aird, W. (2015). A New System for Better Employment and Social Outcomes. Report of the Reference Group on Welfare Reform to the Minister for Social Services.

McGraw, K. O., \& Wong, S. P. (1992). A common language effect size statistic. Psychological Bulletin, 111, 361-365. doi:10.1037/0033-2909.111.2.361.

McKay, S. (2014). Benefits, poverty and social justice. Journal of Poverty and Social Justice, 22, 3-10. doi:10.1332/175982714X13910760153802

Metzer, J. C. (2006). Can volunteering be a moderator of the detrimental effects of engagement in (Un)employment. In T. Kieselbach, A. H. Winefield, H. Another, C. Boyd, S. Anderson (Eds.), Unemployment and Health: International and Interdisciplinary Perspectives (pp. 259-265). Bowen Hills: Queensland.

Morehead, A., \& Griff, C. (1996). Volunteering in Australia. ACOSS Paper(74).

Newton, B., Oakley, J., \& Pollard, E. (2011). Volunteering: Supporting Transitions. London: v: The National Youth Volunteering Service.

Pearce, J. L. (1993). Volunteers: The organizational behavior of unpaid workers. London: Routledge.

Robles, M. M. (2012). Executive perceptions of the top 10 soft skills needed in today's workplace. Business Communication Quarterly, 75, 453-465. doi:10.1177/ 1080569912460400

Saunders, P. (2002). Mutual obligation, participation and popularity: Social security reform in Australia. Journal of Social Policy, 31, 21-38. doi:10.1017/S0047279402006499

Schofield, T. P., \& Butterworth, P. (2015). Patterns of welfare attitudes in the Australian population. PLoS One, 10, e0142792. doi:10.1371/journal.pone.0142792
Schofield, T. P., Haslam, N., \& Butterworth, P. (unpublished manuscript submitted for publication). Disentangling welfare stigma: Characterising the unique contribution of welfare receipt, unemployment and poverty to the perceptions of unemployment benefit recipients.

Shapiro, R. Y., Patterson, K. D., Russell, J., \& Young, J. T. (1987). A report: Employment and social welfare. Public Opinion Quarterly, 51, 268-281. Retrieved from https:// www.jstor.org/stable/2748997

Shore, T. H., \& Tashchian, A. (2013). Perceptions of unemployed workers: Unemployment duration, volunteerism, and age. Journal of Applied Business Research, 29, 983-990. doi:10.19030/jabr.v29i4.7909

Spera, C., Ghertner, R., Nerino, A., \& DiTommaso, A. (2015). Out of work? Volunteers have higher odds of getting back to work. Nonprofit and Voluntary Sector Quarterly, 44, 886-907. doi:10.1177/0899764015605928

Thorndike, E. L. (1920). A constant error in psychological ratings. Journal of Applied Psychology, 4, 25-29. doi: $10.1037 / \mathrm{h} 0071663$

U.S. Census Bureau. (2017). Figure 2: Percent of Population Age 25 and over by Educational Attainment: 1940-2016 Educational Attainment in the United States: 2016. Retrieved from https://web.archive.org/web/ 20170515050129/https:/www.census.gov/content/dam/ Census/library/visualizations/time-series/demo/fig2.jpg

UN Volunteers. (1999). On volunteering and social development, expert working group meeting. Retrieved from http://www.un.mr/vnu07/docs/V4D/

Van Oorschot, W. (1998). Dutch public opinion on social security. Loughborough: Centre for Research in Social Policy.

Van Oorschot, W. (2000). Who should get what, and why? On deservingness criteria and the conditionality of solidarity among the public. Policy \& Politics, 28, 33-48. doi:10.1332/0305573002500811

Vinspired. (2008). Youth volunteering: Attitudes and perceptions. Retrieved from https://preview.tinyurl.com/yct739ql

Warburton, J., \& Smith, J. (2003). Out of the generosity of your heart: are we creating active citizens through compulsory volunteer programmes for young people in Australia? Social Policy and Administration, 37, 772-786. doi:10.1046/j.1467-9515.2003.00371.x

Waytz, A., \& Epley, N. (2012). Social connection enables dehumanization. Journal of Experimental Social Psychology, 48, 70-76. doi:10.1016/j.jesp.2011.07.012

Wiggins, J. S. (1979). A psychological taxonomy of traitdescriptive terms: The interpersonal domain. Journal of Personality and Social Psychology, 37, 395. doi:10.1037/ 0022-3514.37.3.395

Wiggins, J. S. (1991). Agency and communion as conceptual coordinates for the understanding and measurement of interpersonal behavior. In D. Cicchetti \& W. M. Grove (Eds.), Thinking clearly about psychology: Essays in honor of Paul E. Meehl, Vol. 1. Matters of public interest; Vol. 2. Personality and psychopathology (pp. 89-113). Minneapolis: University of Minnesota Press. 